\title{
Design of circular inductive pad couple with magnetic flux density analysis for wireless power transfer in EV
}

\author{
Syasya Azra Zaini, Mohd Shahrin Abu Hanifah, Siti Hajar Yusoff, Nadia Nazieha Nanda, \\ Ahmed Samir Badawi \\ Department of Electrical and Computer Engineering, International Islamic University, Malaysia
}

\begin{tabular}{|c|c|}
\hline Article Info & ABSTRACT \\
\hline Article history: & As the population grows, people will consume more natural resources. This \\
\hline Received Oct 9, 2020 & $\begin{array}{l}\text { issue will lead to a low petrol supply for all land transportation, especially } \\
\text { supplies for car consumption. Therefore, the electric vehicle (EV) has been }\end{array}$ \\
\hline Revised Jun 8, 2021 & introduced to overcome this issue. Currently, wired charging of EVs has been \\
\hline Accepted Jun 15, 2021 & $\begin{array}{l}\text { implemented in most of the developed country, including Malaysia. } \\
\text { However, some drawbacks have been found from this technology. Therefore, }\end{array}$ \\
\hline Keywords: & $\begin{array}{l}\text { wireless charging comes into the picture to solve this issue. Charging pad on } \\
\text { the road and at the car are required for both wired and wireless charging. }\end{array}$ \\
\hline Circular coil pad & Various designs of charging pad are available. However, this paper will only \\
\hline Electric vehicle (EV) & design the coil pad. Each software has a different procedure and steps to \\
\hline JMAG Designer & design the coil pad. In this paper, JMAG Designer software will be used to \\
\hline Magnetic flux density & design the circular coil pad. Then, three coil pair were simulated using \\
\hline Misalignment & JMAG Designer to investigate the magnetic flux density between primary \\
\hline Wireless charging & $\begin{array}{l}\text { and secondary coil when varying the misalignment of } 0 \mathrm{~cm}, 4 \mathrm{~cm} \text { and } 8 \mathrm{~cm} \text {. } \\
\text { From the simulation, there is no specific trend in the relationship between } \\
\text { magnetic flux density and misalignment. }\end{array}$ \\
\hline
\end{tabular}

This is an open access article under the CC BY-SA license.

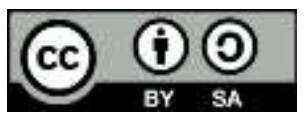

\section{Corresponding Author:}

Mohd Shahrin Abu Hanifah,

Department of Electrical and Computer Engineering,

International Islamic University Malaysia,

Jalan Gombak, 53100 Kuala Lumpur, Malaysia.

Email: nnazieha.nanda@gmail.com

\section{INTRODUCTION}

The consumption of oil after the year 2010 is higher than the production of oil. This situation is very critical because oil production is not being able to meet the demand of the consumers starting from 2010 . Therefore, the use of a fuel car will be irrelevant in the future. Government has introduced electric vehicle (EV) as one of the ways to solve this issue. Electric vehicle (EV) has been introduced in 2012 due to public awareness of the effect of gas emission from the traditional car and the extinction of petroleum natural resources [1]. Besides, EV and plug-in hybrid EV can improve air quality. This ability is because $22 \%$ of the carbon dioxide gas in the air is emitted from transportation [2]. In Malaysia, there are six models of electric car available in the market. Among the models are nissan leaf, mitsubishi motors i-MiEV, BMW i8 and volvo XC90. The use of EV has been implemented in many foreign countries such as China, Canada, Western Europe, Japan and the United States [3]-[5].

There are two ways of charging the EV, which is wired and wireless charging. Wired technique is a traditional way of charging the electric vehicle. Whilst wireless charging of EV offers compactness and safety without any use of a cable due to charging competence [6]-[9]. However, there are some risk and 
hazards when using wireless charging pad. Large power levels from the charging pad will potentially cause electric shock, fire hazards and magnetic field exposure hazards [10]-[12]. Therefore, the charging pad designs have to meet the safety standard set by the international groups before it can be used commercially.

In wireless charging of EV, the coil pad design is among the crucial factor that needs to be considered. Good coil pad design will reduce the loss of power to surrounding due to misalignment and air gap. The designs that have been discussed actively among researchers are circular, rectangular, double-D (DD), double-D quadrature (DDQ). Among many pad designs, the circular pad is the most functional design because of their magnetic properties [13]-[16]. There are various designs of the coil, and each of the designs has its benefit for its specific requirements and applications [17]-[21].

The primary and secondary coil pad system can be represented as the circuit shown in Figure 1 below. The circuit consists of the primary side, where primary inductance $(\mathrm{Lp})$ is the primary coil pad while Ls is the secondary coil pad. This is the series-series compensation topology, the simplest compensation topology among all available compensation topologies [22]-[26].
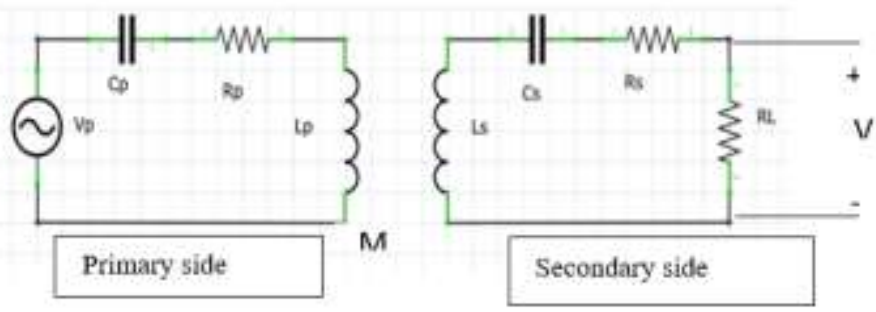

Figure 1. Inductive pad coupler schematic circuit

Before producing the prototype of the circular coil pad, the coil pad was design using specific software for the simulation process. Among the software that can be used is Solidwork, COMSOL Multiphysics and JMAG Designer. Different software has different ways to draw the coil pad.

In this paper, the simulation of coil pad using JMAG Designer software and the magnetic flux density properties were explained. The remaining section of this paper comprises of few main parts. Section 2 will be explaining about the methodology, while section 3 will lay out the simulation results from JMAG Designer software. As a conclusion, the last section will conclude the paper.

\section{METHODOLOGY}

This section will discuss the proposed methodology that is used to design a circular pad. In this section, there will be four subsections; overview design on coil pad, geometric parameters calculation, pad coupler design and simulation in JMAG Designer and evaluation. Subsection 2.1 will discuss the overall process to simulate the coil pad, including calculation and simulations. Whilst subsection 2.2 shows the formula and calculation needed for geometric parameters. Subsection 2.3 describes the flow of the coil design in JMAG Designer software. Lastly, subsection 2.4 is about the simulation and evaluation which will be explained more in section 3 .

\subsection{Overview design on coil pad}

This section will discuss the steps needed to design and simulate the circular coil and to identify the geometric parameters used. The followings are geometric parameters considered in this project; the number of turns $(\mathrm{N})$, inner diameter $(D i)$, and outer diameter (Dout) of coils. Figure 2 shows the step needed in designing geometric properties. Firstly, the geometric parameters are calculated and will be used in designing the pad coupler in JMAG. Later, the completed design of the pad coupler is simulated in the JMAG Designer software. Finally, the evaluation process consists of a magnetic flux density between the two coils were investigated.

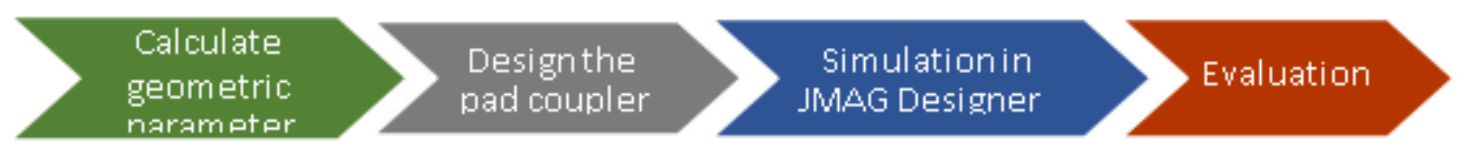

Figure 2. Steps needed to design the geometric properties 


\subsection{Geometric parameters calculation}

The coil pad parameters are calculated using (1) [13], [27]. Di, Dout, L and $\mathrm{N}$ in that equation represents inner diameter, outer diameter, inductance and number of turns of the coil respectively.

$$
\frac{\mathrm{N}^{2}\left(\mathrm{D}_{\text {out }}+\mathrm{D}_{\text {in }}\right)^{2}}{8\left(15 \mathrm{D}_{\text {out }}-7 \mathrm{D}_{\text {in }}\right) 2.54}
$$

Where Din is the inner diameter (in $\mathrm{cm}$ ), $D_{\text {out }}$ is the outer diameter (in $\mathrm{cm}$ ), $\mathrm{L}$ the inductance (in $\mu \mathrm{H}$ ) and $\mathrm{N}$ is the number of turns of coil. Equation on is applied to both primary and secondary inductance calculation in accordance with the parameters involved. Misalignment is calculated horizontally from the centre of the primary coil to the centre of the secondary coil. Whilst air gap distance is measured vertically from the surface of the primary coil to the surface of the secondary coil.

In this project, the value of primary and secondary inductance is $333.9 \mu \mathrm{H}$ and $37 \mu \mathrm{H}$. Table 1 below displays the value for calculated and measured inductance $(\mathrm{L})$, number of turns of coil $(\mathrm{N})$, inner diameter $\left(D_{\text {in }}\right)$ and outer diameter $\left(D_{\text {out }}\right)$. The values of calculated and measured inductance are almost the same and in the acceptable range.

Table 1. Comparison of calculated and measured for inductance and no of turns

\begin{tabular}{cccccc}
\hline $\begin{array}{c}\text { Calculated } \\
\text { inductance }\end{array}$ & $\begin{array}{c}\text { Measured } \\
\text { inductance }\end{array}$ & No. of turns calculated & No. of turns fabricated & Inner diameter $(\mathrm{cm})$ & Outer diameter $(\mathrm{cm})$ \\
\hline $333.9 \mu \mathrm{H}$ & $324.6 \mu \mathrm{H}$ & 45.93 & 43 & 5.5 & 32.5 \\
$37.09 \mu \mathrm{H}$ & $33.3 \mu \mathrm{H}$ & 8.86 & 8 & 22.0 & 26.8 \\
$37.09 \mu \mathrm{H}$ & $35.4 \mu \mathrm{H}$ & 7.86 & 8 & 27.5 & 32.5 \\
$37.09 \mu \mathrm{H}$ & $36.1 \mu \mathrm{H}$ & 6.96 & 7 & 33.0 & 37.0 \\
\hline
\end{tabular}

Then, the diameter of the coil pad is set for each pair. The size of the circular pad for the primary coil is fixed for all coil pairs. However, the secondary coil's diameter is varied. There are three coil pair designs in this project which are $\mathrm{P}-\mathrm{S}_{1}, \mathrm{P}-\mathrm{S}_{2}, \mathrm{P}-\mathrm{S}_{3}$. $\mathrm{P}$ represents the primary coil, while $\mathrm{S}$ represents the secondary coil. The subscript 1,2 and 3 are the three different circular coil design. Table 1 above also shows the geometric parameter of the coil pad. The primary coil is design with $5.5 \mathrm{~cm}$ inner diameter $\left(D_{\text {in }}\right)$ and 32.5 cm outer diameter $\left(D_{\text {out }}\right)$ :

- Coil pair P-S1: The inner diameter of the secondary coil $\left(D_{i n, s}\right)$ is bigger than the primary coil

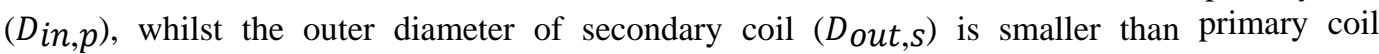

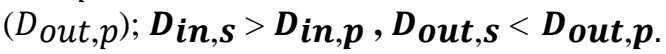

- Coil pair P-S2: The outer diameter of secondary coil $\left(D_{\text {out }, s}\right)$ and primary coil $\left(D_{\text {out }, p}\right)$ is the same while the inner diameter of secondary coil $\left(D_{\text {in }, S}\right)$ is bigger than primary coil $\left(D_{\text {in }, p}\right) ; \boldsymbol{D}_{\boldsymbol{i n}, \boldsymbol{s}}$ $>D_{\text {in }, p}, D_{\text {out }, s}=D_{o u t}, p$.

- Coil pair P-S3: The outer diameter of secondary coil $\left(D_{\text {out }, s}\right)$ is bigger than the primary coil $\left(D_{\text {out }, p}\right)$ while the inner diameter of secondary coil $\left(D_{\text {in }, s}\right)$ is bigger than primary coil $\left(D_{i n, p}\right)$;

$D_{\text {in }, s}>D_{\text {in }, p}, D_{o u t, s}>D_{o u t, p}$.

The misalignment for this simulation is varied between $0 \mathrm{~cm}, 4 \mathrm{~cm}$ and $8 \mathrm{~cm}$ whilst the air gap is fixed to $4 \mathrm{~cm}$. Figure 3 shows the P-S1 coil pair design without misalignment condition. Whilst, Figure 4 illustrates the top view of the coil design with $4 \mathrm{~cm}$ misalignment. This figure is the top view of the coil. The red coil in the Figure below represents the primary coil while brown represent secondary coil.

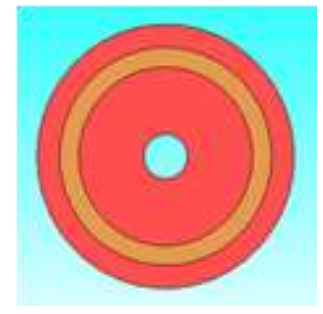

Figure 3. Top view of P-S1 design in JMAG Designer at 0 misalignment

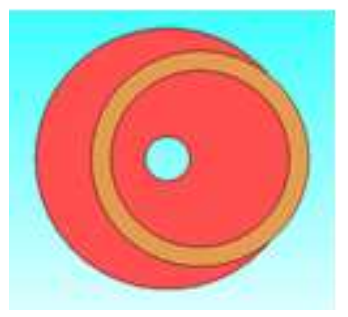

Figure 4. P-S1 design in JMAG Designer at $4 \mathrm{~cm}$ misalignmen 
Figure 3 has no misalignment because the centre of the primary coil is aligned with the secondary coil. However, from Figure 4, the centre of the primary coil is not aligned with the centre of the secondary coil. The distance from the centre of the primary coil to the centre of the secondary coil is $4 \mathrm{~cm}$. The horizontal distance between them is measured and called as misalignment. These two designs of misalignment and without misalignment were used for the simulation in JMAG Designer. Table 2 below shows all the design $\left(\mathrm{P}-\mathrm{S}_{1}, \mathrm{P}-\mathrm{S}_{2}, \mathrm{P}-\mathrm{S}_{3}\right)$ for $0 \mathrm{~cm}, 4 \mathrm{~cm}$ and $8 \mathrm{~cm}$ misalignment in JMAG Designer.

Table 2. Coil pair design at $0 \mathrm{~cm}, 4 \mathrm{~cm}$ and $8 \mathrm{~cm}$ misalignment

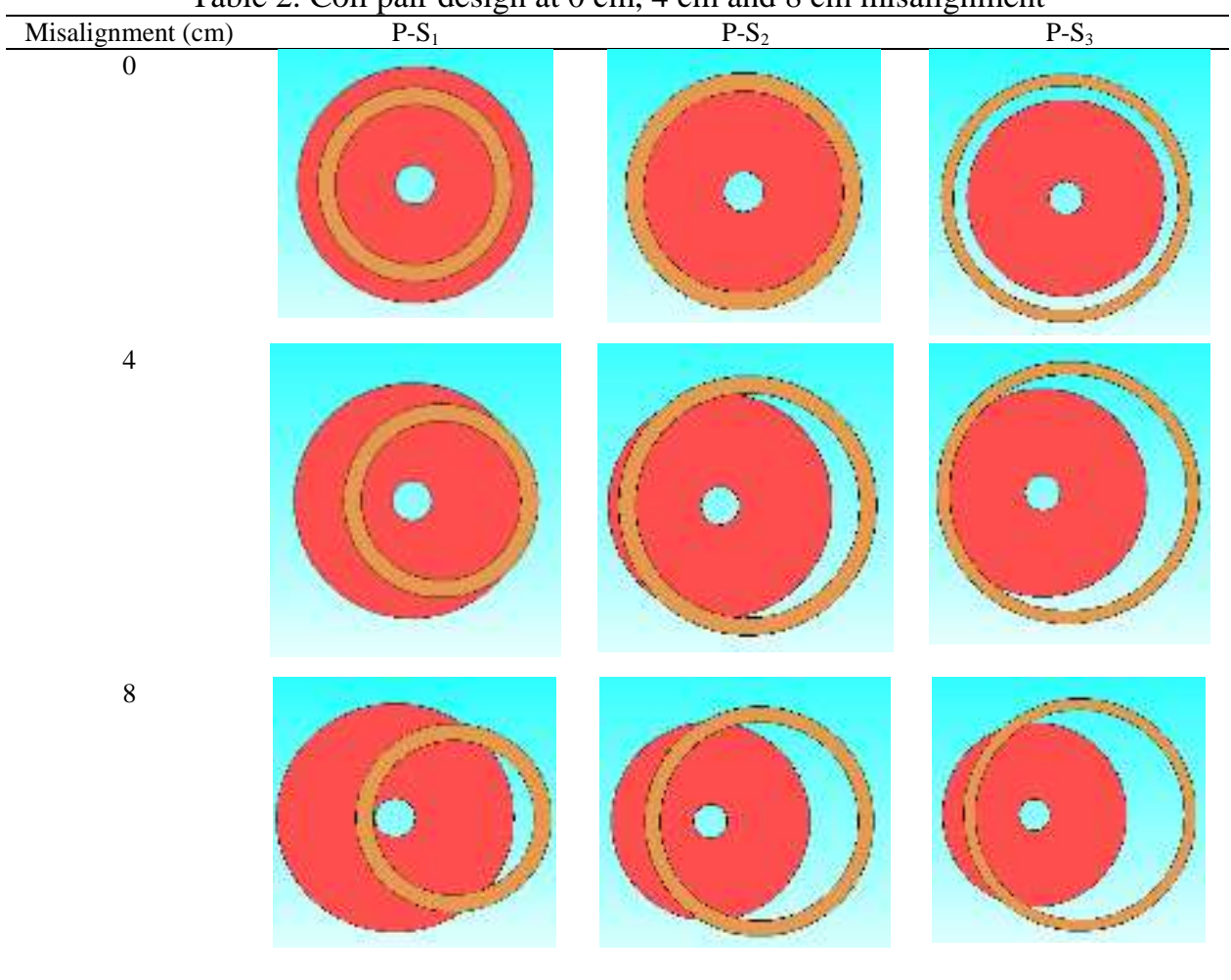

\subsection{Pad coupler design}

There are three main steps in designing the coil pad coupler in JMAG Designer software. The steps are sketching, revolving and circuit construction as shown in Figure 5

Sketch

\section{Construct circuit in JMAG}

Designer

\section{Revolve}

Figure 5. Steps needed to design the circular coil pad in JMAG Designer

\subsubsection{Sketching of circular coil pad}

Based on the information in Table 1 above, the next step is to design these coils based on the $D_{\text {in }}$ and $D_{\text {out }}$ using the JMAG Designer software. The first step in order to design these coils $(\mathrm{P}, \mathrm{S} 1, \mathrm{~S} 2, \mathrm{~S} 3)$ is to sketch a line that represents the inner radius of the coil $\left(\mathrm{R}_{\mathrm{in}}\right)$, and outer radius of the coil $\left(\mathrm{R}_{\text {out }}\right)$ are drawn in the 'Geometry editor' section as illustrated in Figure 5 below. The value of $\mathrm{R}_{\text {in }}$ is taken as $\frac{D_{\text {in }}}{2}$, whilst $\mathrm{R}_{\text {out }}$ is considered as $\frac{D_{\text {out }}}{2}$. Thus, the value of Rin is $165 \mathrm{~mm}$ and $\mathrm{R}_{\text {out }}$ is $185 \mathrm{~mm}$. Figure 6 represents the secondary coil, S3 and the unit used in this sketching is in millimeter ( $\mathrm{mm})$.

These steps of designing the coil pad are repeated for primary coil except that the value of the sketch line that represents the inner radius of the coil $\left(\mathrm{R}_{\text {in }}\right)$ and outer radius of the coil $\left(\mathrm{R}_{\text {out }}\right)$ is now based on Table 1 under primary coil $(P)$ 's parameters [28]. 


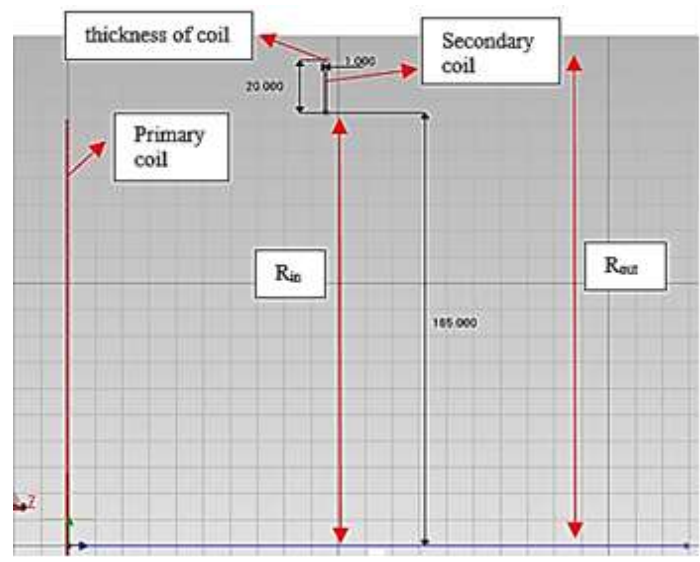

Figure 6. Sketching of the secondary coil, S3 inside the geometry editor using JMAG Designer

\subsubsection{Revolving the sketch}

Now, the secondary coil's sketch is revolved 0o about z-axis as indicated in the blue line shown in Figure 7. In this $0^{\circ}$, the secondary coil is just a line. This initial step is crucial to produce a circular shape. Then, Figure 8 illustrates the secondary coil revolved at $360^{\circ}$ about the z-axis. This step will produce a complete circle and a full design of the coil. After completing the design for each primary and secondary pad, both pads will appear as display in Figure 9. The red colour represents the primary coil $(P)$ while blue colour represents the secondary coil $\left(\mathrm{S}_{3}\right)$.

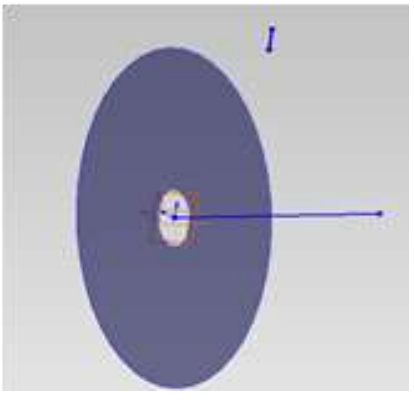

Figure 7. Secondary coil, $\mathrm{S}_{3}$ revolved $0^{\circ}$

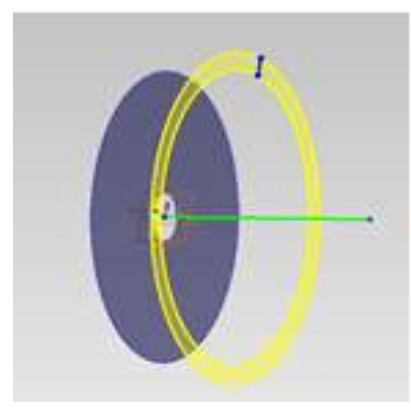

Figure 8. Secondary coil, $\mathrm{S}_{3}$ revolved $360^{\circ}$

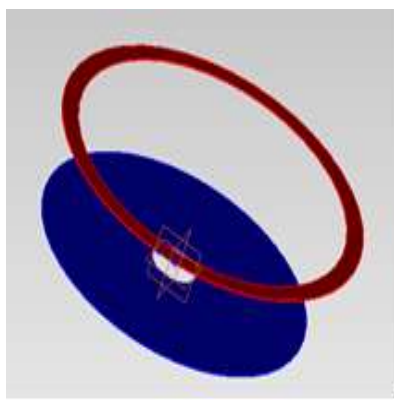

Figure 9. Coil design in the geometry editor of JMAG Designer

\subsubsection{Construct circuit in JMAG Designer}

After completing the sketching process, the model will be imported to the JMAG Designer to study the magnetic properties. Then, a circuit as in Figure 10 which represents both primary and secondary coil will be constructed in this software to state the coil's parameter such as the number of turns, capacitance, load resistor and voltage source. The value for each parameter has been mentioned in Table 1 previously.

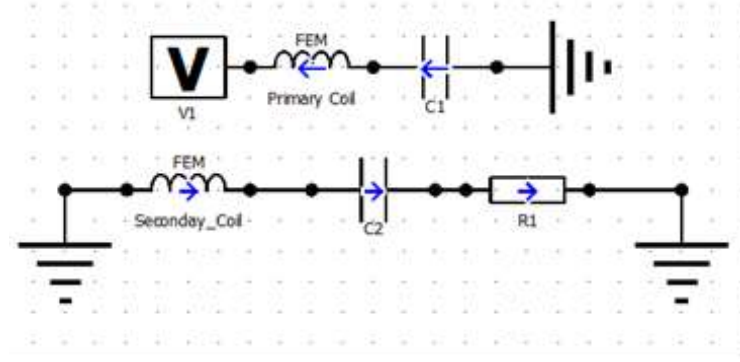

Figure 10. Circuit constructed in JMAG Designer 


\subsubsection{Simulation in JMAG Designer and evaluation}

After completing the parameters calculation and coil design, the simulation will then be initiated. JMAG Designer will run the simulation between coil pad (primary and secondary coil) to study the relationship between each coil design and misalignment towards the magnetic flux density produced. In summarize, there are 4 steps which comprise of geometric parameters calculation, pad coupler design, simulation using the JMAG Designer software and evaluation. The results for the magnetic flux density simulation will be explained in section 3 .

\section{SIMULATION RESULTS}

In JMAG Designer, the designed coil pairs are simulated to observe and measure the value of magnetic flux density. For each pair, the simulations are fixed to $4 \mathrm{~cm}$ air gap and varying the misalignment from $0 \mathrm{~cm}, 4 \mathrm{~cm}$ and $8 \mathrm{~cm}$. Design 1 in Table 3 shows the magnetic flux density for $P-S_{1}$ pair at $0 \mathrm{~cm}, 4 \mathrm{~cm}$ and $8 \mathrm{~cm}$ misalignment position respectively. The colour legend provided on the right of the simulated coil indicates the magnetic flux density distribution in a coil. Even though the highest magnetic flux value in the colour legend is represented by red colour, but the optimum magnetic flux density for this condition is between orange and red region (5.3333E-04 $\mathrm{T}$ to $6.0000 \mathrm{E}-04 \mathrm{~T}$ ). This orange region value is written as the maximum magnetic flux density of 5.8004E-04 $\mathrm{T}$ written below the colour legend. The red colour may indicate the highest, but it is not optimum because the fluxes are too saturated, thus not ideal for power transfer.

Table 3. Magnetic reflux coil pair design at $0 \mathrm{~cm}, 4 \mathrm{~cm}$ and $8 \mathrm{~cm}$ misalignment

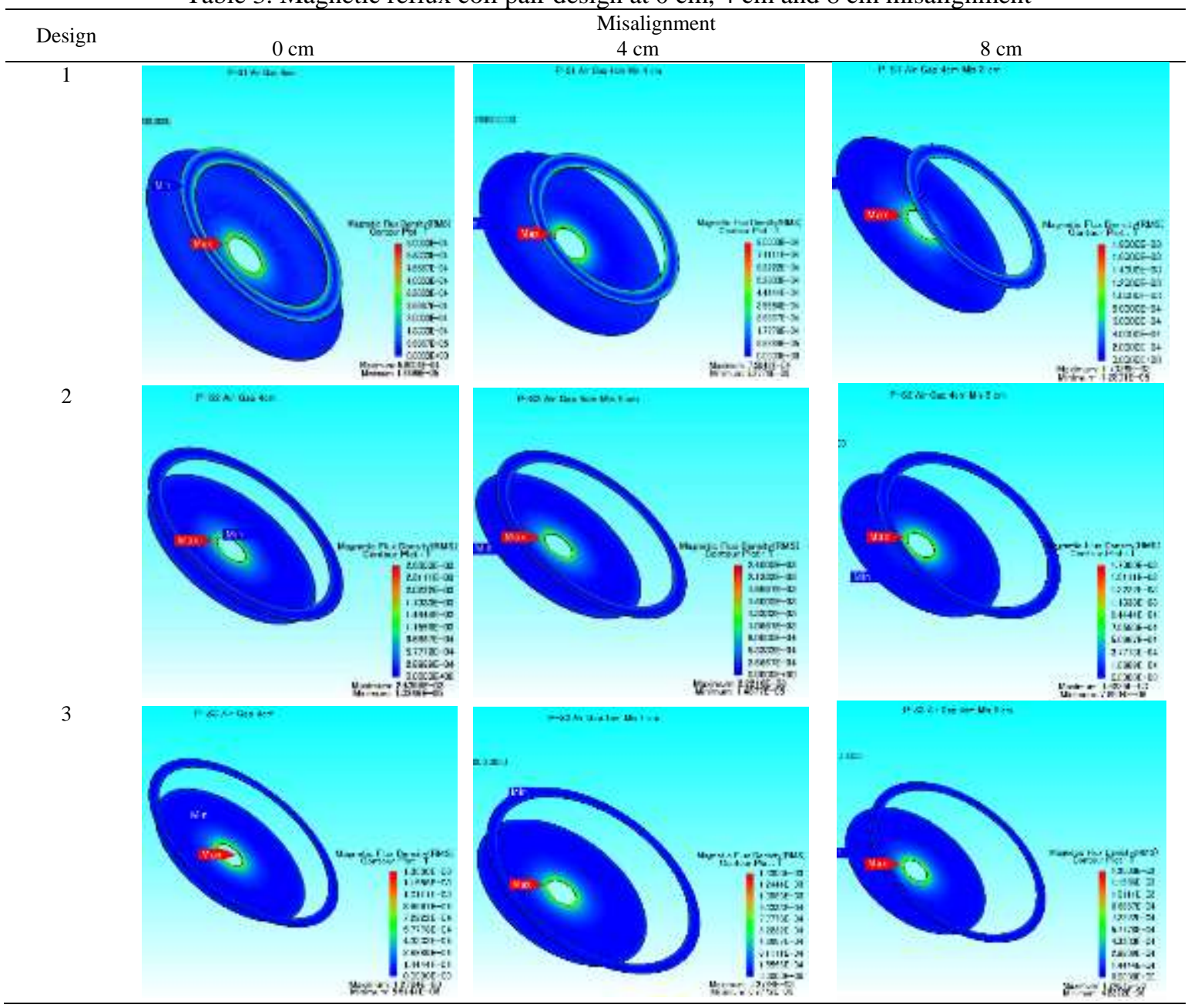

From design 1 for all misalignments in Table 3, it can be seen that the magnetic flux density value for P-S pair is different at different misalignment condition. At $0 \mathrm{~cm}$ misalignment, the magnetic flux density value at the primary coil is low, which is 5.008E-04 T. However, as the misalignment between primary and secondary coil increases, the magnetic flux density increases as well until it reaches $1.733 \mathrm{E}-03 \mathrm{~T}$ at $8 \mathrm{~cm}$ misalignment. 
Design 2 is P-S2 coil pair was sketched and simulated in JMAG Designer. This design has a similar outer diameter $\left(\mathrm{D}_{\text {out }}\right)$ value for the primary and secondary coil, which is $32.5 \mathrm{~cm}$. The simulated results at 0 $\mathrm{cm}, 4 \mathrm{~cm}$ and $8 \mathrm{~cm}$ misalignment are shown in Table 3. $\mathrm{P}-\mathrm{S}_{2}$ pair has high magnetic flux density around $2.4396 \mathrm{E}-03 \mathrm{~T}$ at $0 \mathrm{~cm}$ misalignment. However, as the misalignment between primary and secondary coil increases, the magnetic flux density decreases as well until it reaches $1.6629 \mathrm{E}-03 \mathrm{~T}$ at $8 \mathrm{~cm}$ misalignment.

Design 3 is $\mathrm{P}-\mathrm{S}_{3}$ coil pair where the outer diameter $\left(\mathrm{D}_{\text {out }}\right)$ secondary coil is $37 \mathrm{~cm}$ whilst primary coil is $32.5 \mathrm{~cm} . \mathrm{P}-\mathrm{S}_{3}$ pair has low magnetic flux density around $1.2784 \mathrm{E}-03 \mathrm{~T}$ at $0 \mathrm{~cm}$ misalignment. However, as the misalignment between primary and secondary coil increases, the magnetic flux density decreases as well until it reaches $1.2407 \mathrm{E}-03 \mathrm{~T}$ at $8 \mathrm{~cm}$ misalignment. A graph that compares the maximum magnetic flux density for all three designs $\left(\mathrm{P}-\mathrm{S}_{1}, \mathrm{P}-\mathrm{S}_{2}, \mathrm{P}-\mathrm{S}_{3}\right)$ are expressed in Figure 11.

Figure 11 shows that misalignment affects the magnetic flux density value. When comparing $\mathrm{P}-\mathrm{S}_{1}$ coil pair and $\mathrm{P}-\mathrm{S}_{2}$ coil pair at $0 \mathrm{~cm}$ misalignment, $\mathrm{P}-\mathrm{S}_{2}$ pair has higher magnetic flux density. The trend of magnetic flux density value over misalignment for $\mathrm{P}-\mathrm{S}_{2}$ design is different comparing to $\mathrm{P}-\mathrm{S}_{1}$, where the trend is increasing in contrast to $\mathrm{P}-\mathrm{S}_{1}$. Furthermore, $\mathrm{P}-\mathrm{S}_{3}$ design gives a lower value of magnetic flux density than $\mathrm{P}-\mathrm{S}_{2}$ pair but higher than $\mathrm{P}-\mathrm{S}_{1}$ pair at $0 \mathrm{~cm}$ misalignment. The magnetic flux density value for $\mathrm{P}-\mathrm{S}_{3}$ at $0 \mathrm{~cm}$ misalignment is $1.278 \mathrm{E}-03 \mathrm{~T}$ which is the second-highest after $\mathrm{P}-\mathrm{S}_{2}$. Therefore, these simulation results show that the magnetic flux density distribution at $\mathrm{P}-\mathrm{S}_{1}$ coil is the lowest among the other two design $\left(\mathrm{P}-\mathrm{S}_{2}, \mathrm{P}-\mathrm{S}_{3}\right)$.

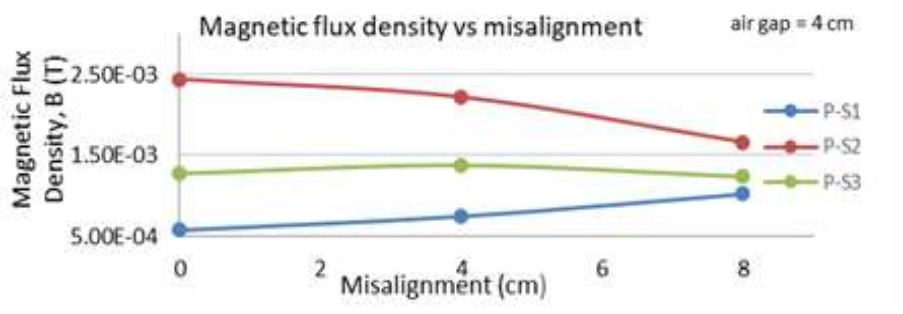

Figure 11. Magnetic flux density for all three coil pairs design for air gap 4cm

\section{CONCLUSION}

This paper has successfully investigated the magnetic flux density value for each coil pair $\left(\mathrm{P}-\mathrm{S}_{1}, \mathrm{P}\right.$ $\mathrm{S}_{2}, \mathrm{P}-\mathrm{S}_{3}$ ) under different misalignment condition at fix air gap. The coil pairs were design and simulated using JMAG Designer software. Overall, there are no specific trend in the relationship between magnetic flux density and misalignment. The above results were due to the different design of the coil pair used in this project which give the different effect of the magnetic flux distribution in a coil. Low magnetic flux will be produced between two coils when the primary and secondary coil gets further apart, and the surface area of these coils are not aligned. Therefore, the low value of magnetic flux density between the coils will then induced low current, which then gives low power transfer. Thus, $\mathrm{P}-\mathrm{S}_{2}$ is the best design in terms of magnetic flux density from this simulation following by $\mathrm{P}-\mathrm{S}_{3}$ and $\mathrm{P}-\mathrm{S}_{1}$.

\section{ACKNOWLEDGEMENTS}

This work was partially supported under Research Initiative Grant Scheme (RIGS) number RIGS17053-0628 and the International Islamic University Malaysia under the Kulliyyah of Engineering Postgraduate Tuition Fee Waiver Scheme 2019 (TFW2019).

\section{REFERENCES}

[1] Bolger, J. G., Ng, L. S., Turner, D. B., and Wallace, R. I., "Testing a prototype inductive power coupling for an electric highway system," 29th IEEE Vehicular Technology Conference, vol. 29, 1979, pp. 48-56, doi: 10.1109/VTC.1979.1622664.

[2] Malaysian Green Technology Corporation, Low Carbon Mobility, 2016. [Online]. Avalable: https://www.mgtc.gov.my/our-services/low-carbon-mobility/

[3] Office of Energy Efficiency \& Renewable Energy, FACT \#918: March 28, 2016 Global Plug-In Light Vehicle Sales Increased By About 80\% IN 2015, 2016. [Online]. Available: https://www.energy.gov/eere/vehicles/fact-918-march-282016-global-plug-light-vehicle-sales-increased-about-80-2015

[4] J. G. Gear, "Ge uses ai to charge electric cars without running up the bill," 2014. [Online]. Available: https://www.wired.com/2014/12/ge-nyc-electric-car-charging/

[5] A. Mackenzie, "Bosch and Evatran partner to bring EV wireless charging system to the US," 2013. [Online]. Available: https://newatlas.com/bosch-evatran-inductive-charging-system-ev/27971/ 
[6] N. N. Nanda, S. H. Yusoff, S. F. Toha, N. F. Hasbullah, and N. A. S. Roszaidie, "A Brief Review: Basic Coil Designs for Inductive Power Transfer," Indonesian Journal of Electrical Engineering and Computer Science (IJEECS), vol. 20, no. 3, pp. 1703-1716, 2020, doi: 10.11591/ijeecs.v20.i3.pp1703-1716.

[7] S. Y. R. Hui, W. Zhong, and C. K. Lee, "A Critical Review of Recent Progress in Mid-Range Wireless Power Transfer," IEEE Transactions on Power Electronics, vol. 29, no. 9, pp. 4500-4511, 2014, doi: 10.1109/TPEL.2013.2249670.

[8] W. Chen, J. Liang, Z. Yang, and G. Li, "A review of lithium-ion battery for electric vehicle applications and beyond," Energy Procedia, vol. 158, pp. 4363-4368, 2019, doi: 10.1016/j.egypro.2019.01.783.

[9] R. Chen, C. Zheng, Z. U. Zahid, and E. Faraci, "Analysis and Parameters Optimization of A Contactless IPT System for EV Charger,” 2014 IEEE Appl. Power Electron. Conf. Expo. - APEC 2014, 2014, pp. 1654-1661, doi: 10.1109/APEC.2014.6803528.

[10] H. Jiang, P. Brazis, M. Tabaddor, and J. Bablo, "Safety Considerations of Wireless Charger for Electric Vehicles A Review Paper," 2012 IEEE Symposium on Product Compliance Engineering Proceedings, 2012, pp. 51-56, doi: 10.1109/ISPCE.2012.6398288.

[11] C. Liu, C. Jiang, and C. Qiu, "Overview of coil designs for wireless charging of electric vehicle," 2017 IEEE PELS Workshop on Emerging Technologies: Wireless Power Transfer (WoW), 2017, pp. 1-6, doi: 10.1109/WoW.2017.7959389.

[12] M. Kim, J. Byeon, B. K. Lee, and J. Lee, "Performance analysis of magnetic power pads for inductive power transfer systems with ferrite structure variation," 2016 IEEE Energy Conversion Congress and Exposition (ECCE), 2016, pp. 1-6, doi: 10.1109/ECCE.2016.7855338.

[13] J. T. Boys and G. A. Covic, "The Inductive Power Transfer Story at the University of Auckland," in IEEE Circuits and Systems Magazine, vol. 15, no. 2, pp. 6-27, Secondquarter 2015, doi: 10.1109/MCAS.2015.2418972.

[14] F. Corti, F. Grasso, L. Paolucci, L. Pugi, and L. Luchetti, "Circular Coil for EV Wireless Charging Design and Optimization Considering Ferrite Saturation," 2019 IEEE 5th International forum on Research and Technology for Society and Industry (RTSI), 2019, pp. 279-284, doi: 10.1109/RTSI.2019.8895601.

[15] T. Campi, S. Cruciani, G. Rodríguez, and M. Feliziani, "Coil design of a wireless power transfer charging system for a drone," 2016 IEEE Conference on Electromagnetic Field Computation (CEFC), 2016, pp. 1-1, doi: 10.1109/CEFC.2016.7816070.

[16] B. M. Mosammam, N. Rasekh, M. Mirsalim, and J. S. Moghani, "Comparative Analysis of the Conventional Magnetic Structure Pads for the Wireless Power Transfer Applications," 2019 10th International Power Electronics, Drive Systems and Technologies Conference (PEDSTC), 2019, pp. 624-628, doi: 10.1109/PEDSTC.2019.8697878.

[17] S. A. Zaini, S. H. Yusoff, A. A. Abdullah, S. Khan, F. Abd Rahman, and N. N. Nanda, "Investigation of Magnetic Properties for Different Coil Sizes of Dynamic Wireless Charging Pads for Electric Vehicle (EV)," IIUM Eng. J., vol. 21, no. 1, pp. 23-32, 2020, doi: 10.31436/iiumej.v21i1.1108.

[18] A. Zaheer, H. Hao, G. A. Covic, and D. Kacprzak, "Investigation of Multiple Decoupled Coil Primary Pad Topologies in Lumped IPT Systems for Interoperable Electric Vehicle Charging," in IEEE Transactions on Power Electronics, vol. 30, no. 4, pp. 1937-1955, April 2015, doi: 10.1109/TPEL.2014.2329693.

[19] R. A. Deshmukh and D. B. Talange, "Design of $1 \mathrm{~kW}$ inductive power transfer system for electric vehicle," 2015 International Conference on Technological Advancements in Power and Energy (TAP Energy), 2015, pp. 93-97, doi: 10.1109/TAPENERGY.2015.7229598.

[20] G. Southern et al., "Electric Vehicles Wireless Power Transfer State-of-The-Art," Energy Procedia, vol. 162, pp. 24-37, 2019, doi: 10.1016/j.egypro.2019.04.004.

[21] B. M. Mosammam, N. Rasekh, M. Mirsalim and A. Khorsandi, "Electromagnetic Analysis for DD Pad Magnetic structure of a Wireless Power Transfer (WPT) for Electrical Vehicles," 2018 Smart Grid Conference (SGC), 2018, pp. 1-6, doi: 10.1109/SGC.2018.8777750.

[22] M. A. A. Roslan, N. N. Nanda, and S. H. Yusoff, "Series-Series and Series-Parallel Compensation Topologies for Dynamic Wireless Charging,” Int. Islam. Univ. Malaysia Eng. J., vol. 22, no. 2, 2021, doi: 10.31436/iiumej.v22i2.1660.

[23] K. Aditya and S. S. Williamson, "Comparative study of series-series and series-parallel topology for long track EV charging application,” 2014 IEEE Transportation Electrification Conference and Expo (ITEC), 2014, pp. 1-5, doi: 10.1109/ITEC.2014.6861793.

[24] C. Fang, J. Song, L. Lin, and Y. Wang, "Practical considerations of series-series and series-parallel compensation topologies in wireless power transfer system application," 2017 IEEE PELS Workshop on Emerging Technologies: Wireless Power Transfer (WoW), 2017, pp. 255-259, doi: 10.1109/WoW.2017.7959404.

[25] Y. Chao and J. Shieh, "Series-parallel loosely coupled battery charger with primary-side control," 2012 International Conference on Control, Automation and Information Sciences (ICCAIS), 2012, pp. 226-230, doi: 10.1109/ICCAIS.2012.6466592.

[26] K. Aditya and S. S. Williamson, "Comparative study of Series-Series and Series-Parallel compensation topologies for electric vehicle charging,” 2014 IEEE 23rd International Symposium on Industrial Electronics (ISIE), 2014, pp. 426-430, doi: 10.1109/ISIE.2014.6864651.

[27] K. Aditya, "Design and Implementation of An Inductive Power Transfer System for Wireless Charging of Future Electric Transportation," Doctoral Dissertation, Department Electrical and Computer Engineering, University of Ontario Institute of Technology, Canada, 2016.

[28] S. A. Zaini, "Design of Inductive Pad Coupler in Dynamic Wireless Power Transfer for Electric Vehicle," M.S. Thesis, International Islamic University Malaysia, Malaysia 2019. 